\title{
Reicht sterile Stuhlflüssigkeit zur Heilung?
}

Hintergrund: Die Transplantation von gesundem Spenderstuhl bei Patienten mit wiederholter, auf einer Clostridium difficileInfektion (CDI) beruhenden pseudomembranösen Colitis ist hoch effektiv. Die Erfolgsraten liegen bei 85-90\% nach einem und bis zu $100 \%$ nach zwei Transfers $[1,2]$. Rationale für diese Therapie ist die Verbesserung der intestinalen Dysbiose von CDI-Patienten durch die Übertragung von Stuhlpräparationen mit einem stabilen, lebenden und vielfältigen Mikrobiom von gesunden Spendern. Allerdings birgt die Übertragung unbestimmter Mengen und Arten lebender Bakterien potenzielle, nicht kalkulierbare Risiken für infektiöse, metabolische und maligne Erkrankungen für den Stuhlempfänger [3, 4]. In der vorliegenden Studie wurde getestet, ob der Transfer von Stuhlflüssigkeit, die Zellschutt, DNA-Fragmente und Protein enthält, aber keine lebenden Mikroorganismen, zu einer Besserung oder Heilung der CDI-assoziierten Colitis führt.

Patienten/Methodik: An fünf Patienten mit symptomatischer und rezidivierender CDI wurde eine klinische Fallstudie durchgeführt. Zirka $50 \mathrm{~g}$ Stuhl von fünf gesunden Spendern wurden entsprechend der Stuhltransferstandards aufgearbeitet, anschließend steril filtriert, um alle lebenden Bakterien daraus zu entfernen und als hellbraune, klare und sterile Flüssigkeit einmalig jedem Patienten via Nasojejunalsonde appliziert.

Zwischen Spende und Transfer lagen je $<6$ Stunden. Die Sterilfiltrate wurden mikrobiologisch untersucht, wobei unter aeroben und anaeroben Bedingungen kein Bakterienwachstum nachweisbar war. Stuhlproben der Empfänger wurden vor dem Transfer sowie eine Woche und sechs Wochen nach Transfer gesammelt und untersucht. Mikrobiom-, Virom- und

Ott SJ et al. Efficacy of Sterile Fecal Filtrate Transfer for Treating Patients With Clostridium difficile Infection. Gastroenterology 2017; 152: 99-811
Proteomprofile der Spender und Empfänger wurden verglichen. Alle Patienten wurden sechs bis 33 Monate nachbeobachtet.

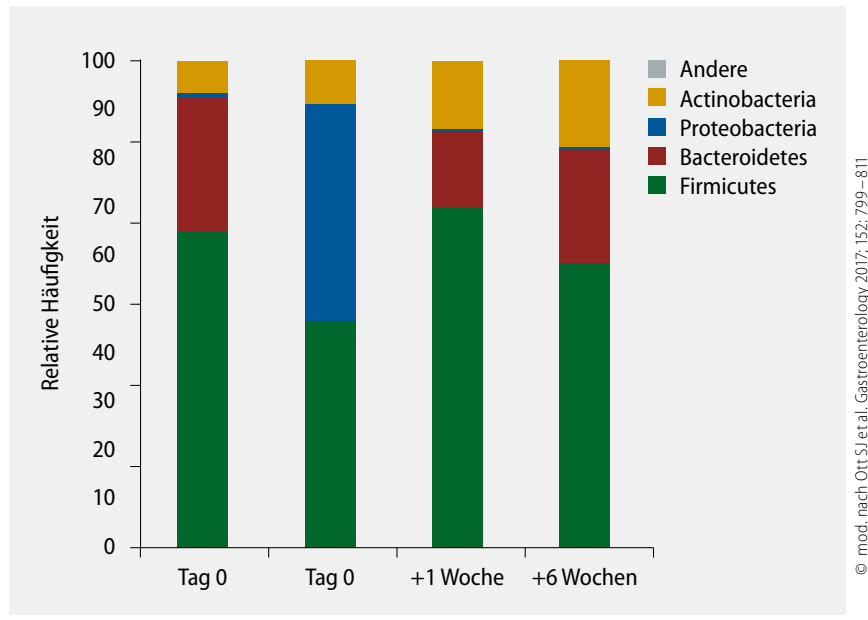

1 Relative Häufigkeit der Bakterienstämme im fäkalen Mikrobiotikaprofil (16S rRNA-Detektion) vor und nach steril filtriertem Stuhltransfer (FFT) bei Patient 3.

Ergebnisse: Zwei bis vier Tage nach dem Steriltransfer zeigte sich eine klare klinische Besserung. Alle Symptome der CDIColitis wurden für mindestens sechs Monate eliminiert. Stuhlgang und Gewicht der Patienten normalisierten sich. Alle Patienten konnten einen Tag nach der Prozedur aus der Klinik entlassen werden. Analysen ergaben verschiedene Bakterien-DNAFragmente im Filtrat $(\triangleright A b b .1)$. Zusätzlich zeigten virologische Analysen Fragmente von Bakteriophagen. In Proteomanalysen der sterilen Stuhlflüssigkeit fanden sich aber keine speziellen Proteinkandidaten, die mit dem therapeutischen Effekt in Zusammenhang gebracht werden konnten. Die Stuhlanalysen der Empfänger zeigten nach Transfer Veränderungen der mikrobiologischen und virologischen Zusammensetzung.

\section{- Kommentar von Constanze Waggershauser, München}

\section{Interessante Alternative für immunsupprimierte Patienten}

In dieser sehr kleinen, aber äußert interessanten Pilotstudie hatte die Übertragung steriler Stuhlflüssigkeit in allen fünf Fällen ein gutes therapeutisches Ansprechen mit Normalisierung der Stuhlgewohnheiten der Patienten zur Folge. Das Ergebnis deutet darauf hin, dass viele therapeutische Effekte eines Stuhltransfers durch bakterielle DNA-Fragmente, Metabolite oder Bakteriophagen vermittelt werden und die potenziell riskante Übertragung lebender Bakterien verzichtbar sein könnte.

Die sterile Stuhltransplantation könnte somit einen alternativen Therapieansatz bei wiederholter pseudomembranöser Colitis darstellen, besonders etwa bei immuninsuffizienten $\mathrm{Pa}$ tienten. Ein weiterer Vorteil dieses Therapieansatzes läge in der besseren Standardisierbarkeit der Prozedur, da es einfacher ist, eine robuste, kostengünstige und patientenfreundliche Stuhlformulierung herzustellen, wenn Bakterien und Sporen nicht notwendigerweise konserviert werden müssen. Das Prinzip sollte zeitnah in größeren Studien mit dem herkömmlichen Stuhltransfer verglichen werden.

\footnotetext{
Literatur

1. Kassam Z et al. Am J Gastroenterol 2013; 108: 500-8

2. Kelly CR et al. Gastroenterology 2015; 149: $223-37$

3. Khoruts A et al. Nat Rev Gastroenterol Hepatol 2016; 13: 508- 16

4. Smiths LP et al. Gastroenterology 2013; 145: 46-53
} 